\title{
O papel das ouvidorias na comunicação pública do Poder Judiciário
}

Henrique Hugueney Romero

Faculdade Católica do Tocantins

Francisco Cláudio Corrêa Meyer Sant'Anna

Faculdade Católica do Tocantins

\section{O papel das ouvidorias na comunicação pública do Poder Judiciário}

Este artigo objetiva propor o debate sobre qual será o papel das ouvidorias judiciais no processo de comunicação social do Poder Judiciário brasileiro. A intenção é iniciar a discussão em busca de quais podem ser as contribuições dessa importante ferramenta de participação popular e promoção da cidadania para a melhoria da comunicação pública realizada pelos tribunais. Essa reflexão se faz necessária no atual cenário em que a sociedade brasileira vem, cada vez mais, exigindo maior transparência da administração pública, mormente após a edição da Lei de Acesso à Informação.

Palavras-chave: ouvidoria, comunicação pública, acesso à informação, poder judiciário, cidadania

\section{El papel de las defensorías del pueblo en el proceso de comunicación social de los tribunales brasileños}

En este artículo se propone un debate sobre cuál es el papel de las defensorías judiciales del pueblo (ombudsman) en los medios de comunicación del proceso de justicia brasileña. La intención es iniciar el debate en la búsqueda de lo que puede ser la contribución de esta importante herramienta de la participación popular y la promoción de la ciudadanía para la mejora de las comunicaciones públicas hechas por los tribunales. Esta reflexión es

Artigo recebido em março de 2014. Versão final em maio de 2014. 
necesaria en el escenario actual en el que la sociedad brasileña está exigiendo cada vez más una mayor transparencia en la administración pública, especialmente después de la promulgación de la Ley de Acceso a la Información.

Palabras clave: defensorías del pueblo, comunicación social, acceso a la información, poder judicial, ciudadanía

\section{The role of judicial ombudsman in the social communication process of the Brazilian courts}

This article aims at proposing a debate on what will be the role of judicial ombudsman in the social communication process of the Brazilian courts. The intent is to initiate a discussion in search of what may be the contributions of this important tool of popular participation and promotion of citizenship to improve public communication made by the courts. This reflection is made necessary in the current scenario in which the Brazilian society is, demanding increasingly more transparency of public administration, specially after the enactment of the Law of Access to Information.

Keywords: ombudsman, public communication, access to information, judiciary branch, citizenship 


\section{Introdução}

Com a crescente demanda da sociedade brasileira pela transparência na gestão pública, sobretudo após a edição da Lei de Acesso à Informação, o papel das ouvidorias públicas assumiu destaque no relacionamento dos diversos órgãos da administração pública com o cidadão usuário dos serviços prestados pelos respectivos órgãos. Neste novo cenário, a população passa a compreender que o cidadão tem direito ao acesso à informação e que a administração pública tem o dever de garantir e facilitar esse acesso, prestando, com eficiência, informação rápida, precisa e de qualidade a toda a sociedade, utilizando-se ativamente dos instrumentos de comunicação pública disponíveis para assegurar a exigida transparência.

Segundo o conceito sintetizado por Jorge Duarte (2011, p. 127), a "comunicação pública se refere à interação e ao fluxo de informações vinculado a temas de interesse coletivo". Nesse contexto, também podemos conceituar transparência, segundo a definição proposta por Mariângela Furlan Haswani (2013, p. 70): “A palavra transparência, quando aplicada aos organismos estatais/governamentais, mantém seu mesmo significado intrínseco: translúcido, que permite ver através de".

O cidadão passa agora a buscar as ouvidorias públicas não mais somente quando precisa se queixar da qualidade dos serviços prestados pelo órgão, mas também busca o atendimento das ouvidorias para obter informações de seu interesse ou de interesse público. A recém-publicada Lei de Acesso à Informação assegura esse direito, independentemente de justificativa. O que se percebe aqui é que a população naturalmente compreendeu o papel de instrumento de comunicação pública das ouvidorias, utilizando-as segundo a classificação proposta por Jorge Duarte (2012, p. 65), que as enquadra como "instrumentos de diálogo", que se caracterizam por "estabelecer instâncias de interação no âmbito da cooperação" e estimular o "exercício da cidadania ativa", sendo considerados pelo autor como "talvez aqueles cuja evolução foi mais constante nos últimos anos. Entre os exemplos estão os fóruns de consulta, oficinas de mobilização social, grupos de trabalho, orçamento participativo, ouvidorias, conselhos".

Dentro da administração pública, um ramo em especial se viu surpreendido pela grande onda de procura pelo acesso à informação. O Poder Judiciário, historicamente marcado pelo fechamento em si próprio, se viu obrigado, por força de lei e pelo anseio popular, a se abrir para a sociedade e se equipar para atender à demanda pelas mais diversas informações, desde o óbvio andamento de um processo judicial ao polêmico vencimento de um magistrado.

Assim, num intervalo inferior a 10 anos, o antes hermético Poder Judiciário passou de um estado de quase total fechamento, para a maioria da população, a uma abertura ampla e forçada. O cidadão comum, que acreditava só poder acessar 
qualquer assunto dentro de um tribunal por meio de um advogado, hoje tem livre acesso às informações judiciais e administrativas de qualquer órgão do Judiciário brasileiro, ressalvados os processos que correm em segredo de justiça.

Esse processo de abertura se iniciou em 30 de dezembro de 2004, com a promulgação da Emenda Constitucional no 45, conhecida como a Reforma do Judiciário. A emenda, entre outras evoluções, criou o hoje famoso Conselho Nacional de Justiça (CNJ), órgão responsável pelo controle da atuação administrativa e financeira do Poder Judiciário. A criação do Conselho se mostrou um marco na modernização e abertura do arcaico Judiciário brasileiro. Trouxe diversos avanços, entre eles a garantia do livre acesso à informação de responsabilidade dos tribunais de todo o País, sejam federais ou estaduais, por parte do cidadão, sobretudo do cidadão brasileiro mais simples, que, como bem observa Hermenegildo Fernandes Gonçalves (2005, p. 81), se via distante e desconfiado da justiça, pois "A linguagem utilizada pelo Poder Judiciário e os trâmites processuais, por si sós, difíceis de compreender, agravam a percepção de distanciamento da população em relação à Justiça".

Hoje, esse processo de abertura vem chegando ao seu ponto de maturação, em grande parte devido à edição da Lei no 12.527 , em novembro de 2011, conhecida como Lei de Acesso à Informação. A nova lei veio, 23 anos depois, regulamentar direitos já garantidos ao cidadão na Constituição Federal de 1988. A lei atendeu aos anseios da sociedade por um acesso realmente eficaz a qualquer tipo de informação da administração pública. Não obstante, mesmo antes da edição da lei, o CNJ já havia determinado aos tribunais de todo o País que criassem, estruturassem e mantivessem as suas ouvidorias. Por meio da sua Resolução 103, editada em fevereiro de 2010, o Conselho estruturou sua própria ouvidoria e determinou aos tribunais que ainda não possuíam ouvidorias que as deveriam criar e equipar num prazo máximo de 60 dias.

O que se viu, então, foi uma rápida criação de ouvidorias judiciais nos diversos tribunais brasileiros e uma melhor estruturação das que já existiam. De modo que, assim que foi sancionada a Lei de Acesso à Informação, as atividades de atendimento ao usuário do Judiciário em busca de informação pública foram prontamente absorvidas pelas ouvidorias recém-criadas e estruturadas.

Assim, no cenário de hoje, esse novo e intenso processo de busca e prestação da informação pública passou a integrar de forma marcante o mecanismo comunicacional das organizações do Judiciário. Tornou-se necessária a reflexão de onde e como se encaixam as atividades das ouvidorias nesse processo de comunicação pública do Poder Judiciário.

Será o papel das ouvidorias judiciais atuar como mero canal de entrada e saída da informação? Ou podem e devem as ouvidorias atuar de forma ativa na gestão 
da informação e no planejamento da política de comunicação dos tribunais brasileiros? O campo ainda é pouco estudado, porém tal reflexão se mostra de grande valia para o aprimoramento da administração pública brasileira, especialmente no que tange ao princípio da transparência, como bem ressalta Luiz Carlos Assis lasbeck:

O avassalador advento das ouvidorias, sobretudo no setor público, é sintoma e consequência de uma mudança de atitude das organizações em relação aos cidadãos, clientes e consumidores, assim como aos fornecedores de produtos e/ou serviços. (IASBECK, 2012, p. 21).

\section{A ouvidoria pública no Brasil}

Historicamente, o conceito moderno de ouvidoria pública surge na Suécia em 1809, com a promulgação da nova constituição sueca. O ouvidor sueco foi criado para funcionar junto ao parlamento, com a função de ligação entre o povo e o governo, fiscalizando a correta aplicação das leis e atividade de juízes, militares e demais funcionários públicos. O modelo de ouvidor sueco, ligado ao parlamento e de atuação independente, vigora até hoje em diversos países da Europa, sendo identificado como ombudsman, palavra que atualmente é sinônimo de ouvidor, como esclarece Vismona (2001, p.11): “Ombudsman, expressão de origem nórdica, resulta da junção da palavra ombud, que significa "representante", "procurador" com a palavra man - homem e não comporta variação (de número ou de gênero)".

Ao longo do século XIX e no início do século XX, o instituto da ouvidoria foi adotado por diversos países do mundo, guardando características peculiares em cada região, de acordo com a cultura política dos países. No caso dos países hispânicos, o ouvidor se chama Defensor del Pueblo, em Portugal é o Provedor de Justiça e na França é o Médiateur. Em quase todos os casos, a função é semelhante: defesa da cidadania, com independência e autonomia, durante um mandato por tempo determinado.

No Brasil, o que se viu inicialmente era diferente do que ocorria na maior parte do mundo. O que existia no Brasil-Colônia era a figura do Ouvidor-Geral, que na verdade não exercia a função de mediação entre a população e o governo, mas era representante da Coroa Portuguesa na colônia brasileira; sua função era ser "os olhos e os ouvidos" do rei de Portugal.

A figura do ouvidor, como a conhecemos hoje, só se consolidou na administração pública brasileira no fim do século XX. Foi em 1999, quando o governo de São Paulo criou o seu sistema de ouvidorias públicas, como relata 
João Elias de Oliveira (2005, p. 51): "A consolidação do sistema de ouvidores e seu principal marco no aspecto legal foi a iniciativa do Governo do Estado de São Paulo, por meio da Lei no 10.294, de 1999, denominada 'Lei de Defesa do Usuário de Serviços Públicos do Estado de São Paulo". No âmbito federal, em 2002 foi criada a Ouvidoria-Geral da União, vinculada à Controladoria-Geral da União.

Em ambos os casos, o que se viu foi a criação de ouvidorias ligadas ao Poder Executivo e com a finalidade de garantir ao cidadão a melhoria da qualidade dos serviços públicos. Após essas duas principais iniciativas, diversos órgãos da administração pública, nas três esferas, passaram a criar e estruturar suas ouvidorias, quase sempre tendo como objetivo atender às reclamações dos usuários.

Além de garantir a possibilidade de reclamar da qualidade dos serviços públicos, essa rede de ouvidorias públicas veio facilitar o acesso do cidadão à informação pública. Assim, a sociedade passou a ter um canal aberto de acesso à informação. Num primeiro momento, o que se notou foi a procura pela informação de uso pessoal. Na sequência, ocorreu a busca pela informação pública com vistas ao controle das atividades da administração pública. Essa busca foi capitaneada, a princípio, por instituições da sociedade civil e pela imprensa, mas logo se espalhou para o cidadão comum, que passou a compreender que o acesso à informação pública é um importante mecanismo de controle social:

Com isso, o cidadão passa a ter um certo controle da administração e pode ajudar a melhorar a qualidade dos serviços prestados. O ouvidor, junto com as informações que apresenta nos relatórios específicos para o dirigente, pode oferecer à instituição os instrumentos gerenciais. E uma instituição moderna vai saber utilizar esses instrumentos para melhorar os seus serviços e produtos. (VISMONA, 2001, p. 166).

Essa busca pela participação popular, pelo controle social e pelo livre acesso à informação pública foi coroada com a recente edição da Lei de Acesso à Informação. A Lei no 12.527 foi sancionada em novembro de 2011 e, mesmo com o ainda pequeno tempo de vigência, já foi capaz de provocar verdadeira revolução na forma como a sociedade vê a informação pública. A administração pública passou a ser obrigada a colocar à disposição do cidadão uma gama de informações até então mantidas encobertas pela burocracia estatal. Além de agora oferecer ao público os chamados portais da transparência, os órgãos também passaram a atender prontamente às mais diversas solicitações por informações.

Para atender a tal demanda, a Controladoria-Geral da União (CGU), por meio da Ouvidoria-Geral da União (OGU), editou, no início de 2012, publicação intitulada "Orientações para a implementação da Lei de Acesso à Informação nas ouvidorias 
públicas". A referida publicação, espécie de cartilha, define diretrizes para que as ouvidorias públicas brasileiras passem a encampar os chamados Serviços de Informação ao Cidadão e, por meio desses, prestem de maneira adequada as informações solicitadas aos órgãos públicos com base na nova lei. A edição é voltada sobretudo para as ouvidorias dos órgãos vinculados ao Poder Executivo, como ministérios e agências reguladoras, por exemplo, mas suas orientações também podem ser aproveitadas por ouvidorias dos demais órgãos estatais, seja na esfera municipal, estadual ou federal, inclusive no Poder Judiciário.

A experiência da Ouvidoria-Geral da União (OGU) é um caso exemplar nas ouvidorias públicas brasileiras. Desde a sua criação, o papel da OGU vem sendo o de estruturar e coordenar uma rede nacional de ouvidorias públicas, criando um sistema de atendimento ao cidadão e dando efetividade ao direito de acesso à informação, garantido pela nova lei:

Esta publicação tem como principal objetivo orientar as ouvidorias na implantação da LAI,(...) é resultado dos conhecimentos anteriormente acumulados pela OGU e também da realização de um estudo sobre a percepção de ouvidores (as) e servidores (as) de dez ouvidorias públicas, vinculadas ao Poder Executivo federal, que compartilharam suas iniciativas, dúvidas e reflexões (CGU, 2012, p. 5).

\section{A ouvidoria e o Poder Judiciário brasileiro}

No Poder Judiciário brasileiro, o cenário hoje é de terreno fértil para a atuação das ouvidorias públicas. Em recente levantamento realizado pela ouvidoria do Conselho Nacional de Justiça, verificou-se que praticamente todos os tribunais do País já possuem suas ouvidorias, devidamente implantadas e estruturadas sendo essa a primeira etapa do processo de criação e estruturação das ouvidorias judiciais concluída no início de 2012, poucos meses após a edição da Lei de Acesso à Informação.

Essa fase de consolidação das ouvidorias judiciais teve início em fevereiro de 2010, com a divulgação da Resolução no 103 do CNJ, que estruturou a ouvidoria do Conselho e determinou a criação de ouvidorias nos tribunais que ainda não as possuíssem. Após a edição da resolução, o próprio CNJ tratou de cobrar dos tribunais, que ainda não tivessem instalado suas ouvidorias, as providências necessárias à criação das referidas unidades. Tal cobrança se deu por meio do processo eletrônico CUMPRDEC - Acompanhamento de Cumprimento de Decisão 100-96.2011.2 -, da relatoria do ministro Cezar Peluso, que, em março de 2012, determinou o arquivamento do processo, tendo em vista o cumprimento da 
resolução, conforme consulta ao sistema de acompanhamento de processos eletrônicos do órgão.

Porém, bem antes da determinação do CNJ, muitos tribunais brasileiros já mantinham suas ouvidorias, sendo a pioneira a do Tribunal de Justiça do Distrito Federal e Territórios (TJDFT), criada em março de 2000, conforme relato de Hermenegildo Gonçalves (2005, p. 82): “Atento aos anseios da sociedade do 3 ㅇ milênio, o Pleno aprovou e o TJDFT se mobilizou para criar essa ferramenta hábil de diálogo com a população por meio da Resolução Administrativa no 03/2000". O TJDFT foi então seguido pela maioria dos tribunais do Brasil, marcando uma tendência. De modo que, já em 2005, cinco anos antes da edição da Resolução 130, cerca de dois terços dos tribunais de justiça já dispunham de ouvidorias, como também ressaltou Gonçalves (2005, p. 82): "felizmente a ideia frutificou e hoje já há 14 tribunais de justiça estaduais com ouvidorias, inclusive o Superior Tribunal de Justiça. Em breve, todos terão ouvidorias, pois essa determinação está na conclusão da Reforma do Poder Judiciário".

Percebe-se, então, que a ordem do Conselho veio para consolidar um quadro já em desenvolvimento e também para dar uma maior uniformidade na estrutura e na atuação das diversas ouvidorias judiciais. Umas das questões fundamentais tratadas na resolução é a obrigatoriedade de que o ouvidor seja um magistrado eleito pelo tribunal e com mandato por tempo determinado. Tal medida trouxe autonomia e legitimidade aos ouvidores, pois, em alguns tribunais, o ouvidor era um servidor do quadro da secretaria, nomeado pelo presidente do órgão, e não um magistrado eleito por seus pares.

Inicialmente, o trabalho das ouvidorias judiciais estava limitado basicamente ao recebimento de reclamações e queixas quanto à qualidade dos serviços prestados pelos órgãos, sobretudo relativas à morosidade processual, característica do Judiciário brasileiro. Os cidadãos que buscavam a Justiça, e também os próprios advogados, perceberam nas ouvidorias dos tribunais uma ferramenta que poderia acelerar a tramitação de seus processos.

Assim, a atividade primordial das ouvidorias judiciais, como era de se esperar, era a de receber a reclamação do usuário, diligenciar junto aos setores competentes em busca da solução do problema relatado pelo cidadão, ou, pelo menos, de uma explicação plausível para o problema, e responder ao usuário/reclamante.

Realmente, esse papel de proporcionar a solução dos conflitos é a principal função das ouvidorias e é sua razão de existir, tornando-a mediadora entre a instituição e os usuários e, assim, contribuindo para a melhoria da imagem e para o aprimoramento da atividade do órgão, como observa Maria de Fátima Veras Vilanova (2005, p. 94): “O cidadão, por intermédio da ouvidoria, participa da gestão 
pública, apontando falhas, omissões, injustiças, cobrando providências, reconhecendo também os méritos da administração, enfim, aferindo a sintonia dos governos com os anseios coletivos".

Após cumprir esse primeiro papel de mediação de conflitos, as ouvidorias do Poder Judiciário receberam uma nova atribuição: a de informar o cidadão. A Lei de Acesso à Informação trouxe também o anseio da sociedade pela transparência. As ouvidorias se tornaram canal de comunicação com o público para a recepção de solicitações por informação pública em poder do tribunal e entrega da informação solicitada ao usuário.

Há que se considerar ainda que, por vezes, o usuário é inclusive um jornalista em busca de dados para reportagens que serão veiculadas para toda a sociedade. Como, por exemplo, se verificou no caso da divulgação dos vencimentos dos magistrados e servidores públicos devido à imposição trazida pela nova legislação, ocasião em que a atuação do CNJ novamente foi fundamental para garantir o acesso à informação pela imprensa e pela população.

Em julho de 2012, diante da resistência de alguns órgãos do Poder Judiciário em divulgar abertamente os dados relativos às remunerações de seus membros e servidores, o Conselho Nacional de Justiça novamente editou resolução exigindo providências aos tribunais brasileiros. A Resolução no 151 do CNJ veio para regulamentar a aplicação da Lei de Acesso à Informação no tocante à divulgação das remunerações, e determinou a publicação pelos tribunais dos referidos dados financeiros, inclusive com a identificação nominal dos beneficiários.

Em seguida, foi aberto o processo CUMPRDEC - Acompanhamento de cumprimento de decisão 4704-66.2012.2 -, para cobrar dos tribunais brasileiros as providências exigidas; ficando, por delegação do Presidente do Conselho Nacional de Justiça, a relatoria do processo a cargo do Conselheiro Wellington Cabral Saraiva, então ouvidor do Conselho. Com base nos dados de atendimento ao usuário da ouvidoria, o conselheiro-ouvidor verificou a crescente procura da sociedade pelas informações sobre as remunerações dos servidores e membros do Poder Judiciário, e diligenciou no sentido de obter mais transparência na divulgação dos referidos dados pelas cortes de justiça, como registrado em relatório trimestral de atividades da ouvidoria do CNJ (2012, p. 22), relativo aos meses de julho, agosto e setembro de 2012: "Para contribuir no atingimento dos objetivos da resolução, a ouvidoria tem realizado levantamento de informações atualizadas, por meio do processo de acompanhamento de cumprimento de decisão".

No caso citado, o que podemos notar é o exemplo de um esforço ativo da instituição da ouvidoria judicial para melhorar a imagem do Poder Judiciário na sociedade brasileira. Apesar de ter uma avaliação popular consideravelmente 
melhor em relação aos demais poderes do Estado, o Judiciário ainda precisa percorrer um longo caminho para obter a tão desejada imagem de eficiência e transparência idealizada quando da Reforma do Judiciário, como bem observa Gaudêncio Torquato:

Em suma, apesar de uma nova postura que se observa nos juízes, muitos tocados pelo ânimo de participação social e pelo sentimento de justiça que corre pelas veias da sociedade, o Poder Judiciário ainda é o mais fechado dos três Poderes. Assim, a imagem do Judiciário tem os seguintes contornos: as decisões de justiça e a jurisprudência formada não são massificadas; o Poder Judiciário é o mais fechado, o mais inacessível; é intocável (TORQUATO, 2008, p. 119).

\section{A ouvidoria e a comunicação pública}

Neste novo panorama nacional das ouvidorias do Poder Judiciário brasileiro, persiste a questão aqui proposta desde o início: qual é o papel das ouvidorias na comunicação pública do Poder Judiciário? Esse questionamento, como já dito, é de suma importância para a compreensão da real importância da atividade das ouvidorias. De modo que, para buscarmos a resposta de tal proposição, se faz necessário responder pelo menos duas outras questões conceituais preliminares.

Primeiramente, a atividade desenvolvida pela ouvidoria é atividade de comunicação social? A fim de analisar essa primeira proposição, podemos iniciar relembrando o modelo básico do processo de comunicação, sintetizado por Haswani (2013, p. 114): "um emissor, que codifica e transmite uma mensagem a um receptor, por meio de um canal; o destinatário recebe, decodifica a mensagem e a responde"; passando, assim, ao conceito de comunicação social, como define Gaudêncio Torquato (2008, p. 34): “a comunicação social, caracterizada por ser um processo indireto, unilateral e público". Em seguida, com base nos dois primeiros conceitos, chegamos à definição de comunicação organizacional, que nos é trazida por Ciro Marcondes Filho (2009, p. 68): "processos comunicativos que se desenvolvem no contexto das organizações sociais e nas interfaces de relacionamento com seus públicos".

Partindo desses conceitos básicos, e considerando que o trabalho de uma ouvidoria é calcado no processo de gestão da informação, recebendo, processando, codificando, recodificando e respondendo mensagens trocadas entre as instituições e os diversos públicos que compõem a sua rede de usuários, podemos facilmente concluir que as ouvidorias realizam, sim, atividades de comunicação social. E essa função comunicativa ocorre não somente quando a ouvidoria presta informações ao cidadão, mas também quando recebe reclamações, como bem observa lasbeck: 
Os problemas trazidos às ouvidorias com rótulo de "reclamações, sugestões, críticas ou dúvidas" são, quase sempre, problemas de comunicação, do ponto de vista do processo propriamente dito, ou seja, são "problemas" porque algo que partiu da organização (de sua expressão) com determinadas intenções foi entendido e "consumido" de forma diversa pelo cliente ou cidadão. (IASBECK, 2010, p. 19).

O segundo questionamento conceitual pode ser colocado da seguinte maneira: as atividades desenvolvidas pelas ouvidorias do Poder Judiciário são atividades de comunicação pública? Logo, faz-se premente nos dedicarmos ao conceito de comunicação pública. A princípio, Jorge Duarte (2011, p. 126) já nos alerta sobre a abrangência do referido conceito, que, na sua visão, engloba, entre outros, os conceitos de comunicação governamental e de comunicação política, pois "inclui tudo o que está relacionado ao aparato estatal, às ações governamentais, a partidos políticos, ao Legislativo, ao Judiciário, ao terceiro setor, às instituições representativas, ao cidadão individualmente e, em certas circunstâncias, às ações privadas". Mariângela Furlan Haswani (2013, p. 120) tem opinião semelhante: "comunicação pública compreende processos diversos e faz interagir atores públicos e privados na perspectiva de ativar a relação entre o Estado e os cidadãos, com o intuito de promover um processo de crescimento civil e social".

Para conhecermos um pouco mais do conceito de comunicação pública, é importante recorrer a Margarida Kunsch (2011, p. 15), que entende a "comunicação pública na vinculação com o interesse público, do ponto de vista tanto da teoria quanto da práxis" e que "pode ser vista como uma rede, simbolicamente construída, a partir de temas relevantes para o interesse público, de caráter transitório ou permanente". Também conceitua, no tocante à comunicação pública, Elizabeth Pazito Brandão (2012, p. 29): "diz respeito a um processo comunicativo que se instaura entre o Estado, o governo e a sociedade com o objetivo de informar para a construção da cidadania".

Enfim, podemos afirmar que, mais do que comunicação social, a função comunicativa realizada pelas ouvidorias do Poder Judiciário, além de comunicação organizacional, também deve ser compreendida como atividade de comunicação pública, visto que estabelece a comunicação entre os órgãos públicos e os cidadãos. Na verdade, como vimos, as ouvidorias judiciais vêm a cada dia mais realizando importante papel na comunicação das organizações públicas, pois, como afirmam Ailim Braz e Rafiza Varão:

É assim que se pode definir, enfim, o papel da ouvidoria na comunicação organizacional, como um 'lugar' de trocas informacionais e comunicacionais intensas entre o interno e o externo, que se caracteriza não só pelo ato de 
ouvir, mas pelo processamento e análise, gerando respostas da organização com seu público, aferindo e consolidando a imagem da instituição. (Braz; VARÃo, 2012, p. 72).

\section{Conclusão}

A primeira conclusão que podemos obter é de que as ouvidorias exercem, sim, papel importante dentro do processo de comunicação dos tribunais que compõem o Poder Judiciário brasileiro. Em segundo lugar, podemos concluir que esse papel ainda está em fase de definição, visto que, somente muito recentemente, todos os tribunais passaram a contar com o instituto da ouvidoria funcionando plenamente. Também é recente a atuação dessas ouvidorias como canal de comunicação com a sociedade para o acesso à informação. Assim, surge uma terceira e conseguinte conclusão: é urgentemente necessário que o Poder Judiciário defina melhor esse papel, de modo a integrar de forma definitiva esse importante órgão de promoção da cidadania, que é a ouvidoria, no seu processo de comunicação pública.

Não é o objetivo aqui esgotar esse debate; muito pelo contrário, a intenção primeira é a de promover a reflexão necessária para a correta definição do papel das ouvidorias na comunicação pública do Judiciário. Nesse sentido, é interessante apontar algumas sugestões para o aprimoramento da atuação das ouvidorias nesse contexto.

Em primeiro lugar, é de suma importância que os tribunais tenham claro o conceito de ouvidoria como "um instrumento eficaz de contato, um canal de comunicação entre o órgão público e seu usuário, o cidadão" (VISMONA, 2001, p. 166).

Em segundo lugar, as ouvidorias devem tomar para si as atividades decorrentes da Lei de Acesso à Informação como oportunidade de fomentar a construção da cidadania, prestando de forma eficaz as informações solicitadas pelo cidadão e, assim, incentivando a participação popular, o controle social e o livre acesso aos dados da administração pública.

E a terceira sugestão é a de que as atividades das ouvidorias e das assessorias de comunicação social dos órgãos do Poder Judiciário sejam integradas, de modo a se aproveitar corretamente a riqueza da troca de informação para aprimorar a política de comunicação social dos tribunais. Essa integração trará certamente inúmeros benefícios para a administração pública e para o cidadão, como a criação de campanhas de propaganda mais alinhadas com as necessidades do público, por exemplo, pois é fundamental acompanhar as evoluções da sociedade atual.

Por fim, é importante destacar que essas e outras melhorias no processo de definição do papel das ouvidorias judiciais na comunicação pública do Poder 
Judiciário só serão efetivamente alcançadas quando a ouvidoria do Conselho Nacional de Justiça, a exemplo da Ouvidoria-Geral da União, se tornar o órgão de cúpula de um sistema nacional de ouvidorias judiciais, de modo a integrar e coordenar as atividades das ouvidorias dos tribunais brasileiros, nos moldes do que está previsto na Constituição Federal, em seu artigo 103-B, paragrafo sétimo, desde a promulgação da Emenda Constitucional no 45, de 2004, conhecida como Reforma do Judiciário:

§ 70 A União, inclusive no Distrito Federal e nos Territórios, criará ouvidorias de justiça, competentes para receber reclamações e denúncias de qualquer interessado contra membros ou órgãos do Poder Judiciário, ou contra seus serviços auxiliares, representando diretamente ao Conselho Nacional de Justiça. (BRASIL, 2006, p. 82).

\section{Referências bibliográficas}

Brandão, Elizabeth Pazito, Conceito de comunicação pública. In: DuARTE, Jorge (org.). Comunicação Pública: Estado, governo mercado, sociedade e interesse público. São Paulo: Editora Atlas, 2012.

Brasıl. Constituição da República Federal do Brasil: 1988. Brasília: Câmara dos Deputados, Coordenadoria de Publicações, 2006.

Braz, A.; VARÃo, R.. O papel das ouvidorias na comunicação organizacional. In: IASBECK, Luiz Carlos (org.). Ouvidoria: mídia organizacional. Porto Alegre: Editora Sulina, 2012. Conselho Nacional De Justiça. 11 o Relatório Trimestral da Ouvidoria do Conselho Nacional de Justiça: Julho a setembro de 2012. Disponível em: <http:// www.cnj.jus.br/images/stories/docs_cnj/ouvidoria/relatorios/2012/Ouvidoria_ 11_Relatorio_Trimestral_2012_jul_set.pdf>. Acesso em: 12 de agosto 2013.

Controladoria Geral Da União. Orientações para a implementação da lei de Acesso à Informação nas ouvidorias públicas: rumo ao sistema participativo. Brasília: CGU, 2012.

DUARTE, Jorge. Instrumentos de comunicação pública. In: DUARTE, Jorge (org.). Comunicação Pública: Estado, governo mercado, sociedade e interesse público. São Paulo: Editora Atlas, 2012.

. Sobre a emergência do(s) conceito(s) de comunicação pública. In: Kunsch, Margarida Maria (org.). Comunicação pública, sociedade e cidadania. São Caetano do Sul: Editora Difusão, 2011.

HASWANı, Mariângela Furlan. Comunicação pública: bases e abrangências. São Paulo: Saraiva, 2013.

GonçALVES, Hermenegildo Fernandes. Ouvidorias Judiciárias. In: VISMONA, Edson Luiz (org.). A ouvidoria brasileira: dez anos da Associação Brasileira de Ouvidores/ Ombudsman. São Paulo: Imprensa Oficial do Estado de São Paulo, 2005. 
IASBECK, Luiz Carlos. Ouvidoria é comunicação. In: Organicom: Revista Brasileira de Comunicação e Relações Públicas, São Paulo, Ano 7, n. 12, 2010.

. Competências comunicacionais em ouvidorias. In: IASBECK, Luiz Carlos (org.). Ouvidoria: mídia organizacional. Porto Alegre: Editora Sulina, 2012. Kunsch, Margarida Maria (org.). Comunicação pública, sociedade e cidadania. São Caetano do Sul: Editora Difusão, 2011.

Marcondes Filho, Ciro (org.) Dicionário de comunicação. São Paulo: Paulus, 2009.

Oliveira, João Elias de. Ouvidoria pública brasileira: a evolução de um modelo único. In: VISMONA, Edson Luiz (org.). A ouvidoria brasileira: dez anos da Associação Brasileira de Ouvidores/Ombudsman. São Paulo: Imprensa Oficial do Estado de São Paulo, 2005.

ToRquato, Gaudêncio. Tratado de comunicação organizacional e política. São Paulo: Cengage Learning, 2008.

VILANova, Maria de Fátima Veras. Evolução das ouvidorias universitárias no contexto das ouvidorias brasileiras. In: VISMONA, Edson Luiz (org.). A ouvidoria brasileira: dez anos da Associação Brasileira de Ouvidores/Ombudsman. São Paulo: Imprensa Oficial do Estado de São Paulo, 2005.

VISMOnA, Edson Luiz. A experiência dos Ouvidores Públicos. In: Cadernos FUNDAP, São Paulo, n. 22, 2001.

VISMONA, Edson Luiz (org.). A ouvidoria brasileira: dez anos da Associação Brasileira de Ouvidores/Ombudsman. São Paulo: Imprensa Oficial do Estado de São Paulo, 2005.

Henrique Hugueney Romero

Estudante de Pós-Graduação MBA em Comunicação e Marketing da Faculdade Católica do Tocantins. Contato: henriqueromero79@gmail.com

Francisco Cláudio Corrêa Meyer Sant’Anna

Doutor em Ciências da Informação e Comunicação pela Universite de Rennes I (U.R.I.), França. Professor da Faculdade Católica do Tocantins. Contato: franciscoc.santanna@gmail.com 